\title{
Improving health-promoting self-care in family carers of people with dementia: a review of interventions
}

\section{Deborah Oliveira' \\ Lidia Sousa ${ }^{2}$ \\ Martin Orrell'}

'Division of Psychiatry and Applied Psychology, Institute of Mental Health, School of Medicine, University of Nottingham, Nottingham, UK; ${ }^{2}$ Department of Psychiatry and Mental Health, Santa Maria University Hospital, Lisbon, Portugal
Correspondence: Deborah Oliveira Post-Graduation Programme, Department of Psychiatry and Department of Psychobiology, Federal University of Sao Paulo (UNIFESP), 925 Napoleão de Barros, Ist floor, 04024-002, Vila Clementino,

São Paulo, SP, Brazil

Tel +55 II 21490155

Email oliveiradc.phd@gmail.com
This article was published in the following Dove Medical Press journal: Clinical Interventions in Aging

Background: Providing care for a family member with dementia can leave little time for carers to look after their own health needs, which makes them more susceptible to mental and physical health problems. This scoping review aimed to explore potential health benefits of interventions aimed at improving health-promoting self-care in family carers of people with dementia.

Methods: A scoping review was carried out using Arksey and O'Malley's methodological framework. EMBASE, MEDLINE, PsycINFO and Google Scholar were consulted. Original and peer-reviewed research published in English up to April 2017 were included. Publications were selected by two reviewers independently. Eight experts from several countries provided extra relevant information, which was triangulated with the review results. A narrative approach was used to describe and discuss the review findings.

Results: Seven interventions were identified. These were highly heterogeneous in content, method of delivery, and outcome measures. None was specifically focused on improving and evaluating health-promoting self-care, instead they often focused on health promotion and healthy lifestyle (eg, physical activity). Some of the multi-component interventions included "self-care" as a domain, but none used a specific measure of health-promoting self-care, so we were unable to affirm that the improvements found in the interventions were due to an improvement in this area. Interventions helped reduce carer depression and burden and increased quality of life, positive affect, and physical activity. The expert panel recommended to consider carers' preparedness and capacity to adhere to self-care practices, as well as carers' age and culture. Future interventions should be context specific, flexible, and person-centered.

Conclusion: Psychosocial interventions may improve health-promoting self-care behavior, but more research is needed to establish efficacy. Interventions should be flexible, use a personcentered approach, be implemented with fidelity and use the right dosage.

Keywords: Alzheimer's disease, dementia, carers, health promotion, scoping review, self-care, psychosocial interventions

\section{Introduction}

Caring for a family member with dementia can have negative consequences for the physical and mental health of family carers due to the high levels of burden, stress, and loneliness often resulting from this role. ${ }^{1,2}$ Carers can be reluctant or unable to seek help for health issues due to intense caring routines and psychological difficulties, such as guilt, ${ }^{1,3}$ which may lead to a higher number of illnesses and higher mortality rates, as well as increased hospital admissions and care-home placement for the person cared for. ${ }^{4,5}$ Understanding how family carers can care for their own health better may potentially contribute to a reduction in the negative health and well-being effects of caring for someone with dementia. ${ }^{6-8}$ (c)
hereby accept the Terms. Non-commercial uses of the work are permitted without any further permission from Dove Medical Press Limited, provided the work is properly attributed. For permission for commercial use of this work, please see paragraphs 4.2 and 5 of our Terms (https://www.dovepress.com/terms.php). 
Health-promoting self-care comprises the actions taken by individuals to improve their health, maintain good functioning, and increase well-being, in response to illness or simply to promote health. ${ }^{9,10}$ This enables services to support people to identify and develop their own strengths and abilities to meet their needs, according to their own capabilities and preferences. ${ }^{10}$ Improving self-care behavior is relevant not only for preventing health issues, but also in mediating the course of long-term conditions. ${ }^{11}$ This has the potential to empower individuals with chronic conditions to better look after their own health, helping inform day-to-day decisions and management of illnesses and health, ${ }^{12-16}$ improving adherence to treatment, quality of life, patients' knowledge of their illness, and self-management. ${ }^{17}$ In doing that, care programs can be optimized as individuals are encouraged to depend less on services to have a healthy life, which in turn may reduce service costs. ${ }^{18}$

Health-promoting self-care is a key strategic area within national and international health policies and we need to know how to promote this for carers. ${ }^{19}$ Health-promoting self-care can be considered an outcome in its own right as it reflects people's overall ability to care for their own health and well-being and may have impact across their lifespan. However, it may also function as a mediating variable in the sense that individuals' health and well-being could be improved through the increase in levels of health-promoting self-care. Much of the health-related research on family carers is about the negative experiences or problems arising from the caregiving role and is based on stress-coping frameworks. ${ }^{9}$ There is limited evidence on the approaches to health-promoting self-care in family carers of people with dementia and its potential benefits to carers' health and well-being. Therefore, this scoping review aimed to explore the potential benefits of interventions aimed at improving health-promoting behavior, which could potentially be implemented in public health services to help family carers look after their own health better.

\section{Material and methods}

A scoping review method was adopted as it was aimed at exploring more broadly the potential benefits and research gaps to inform a future systematic review on this topic. ${ }^{20}$ A transparent approach to data selection, collection, and analysis was used to produce a broad map of the literature. ${ }^{21}$ A scoping review framework ${ }^{22,23}$ was used to ensure the quality and robustness of the review, in line with Cochrane recommendations. ${ }^{21}$ This framework has six sequential steps: 1) identifying the research questions; 2) identifying relevant studies; 3) study selection; 4) charting the data; 5) collating, summarizing, and reporting the results; and 6) expert consultation.

\section{Search strategy}

This literature search was guided by the following research question: what are the benefits of health-promoting self-care attitudes, behavior, approaches, and interventions most commonly used by or with family carers of people with dementia?

The following keywords were used for the literature search: (dementia OR Alzheimer's disease) AND (caregivers OR carers OR informal care OR non-professional care OR non-formal care OR family care OR unpaid care) AND (health OR health status OR mental health OR physical health OR health care need OR health need OR health issue OR health problem OR unmet need OR health literacy OR health behavior OR health behavior OR health belief model OR health belief OR attitude to health OR health attitude OR self-management or self management OR self-care OR selfefficacy OR self-regulation OR autoregulation OR self-care agency OR self-care agency).

EMBASE, MEDLINE, PsycINFO, and Google Scholar databases were used to identify relevant studies. The search strategy was adapted to the requirements of each database, using appropriate Boolean operators and coding to increase search sensitivity. The references of included papers were also checked for any relevant information.

\section{Inclusion criteria}

All papers published prior to the search date (April 2017) were considered. Only original and peer-reviewed research published in English were included. No inclusion/exclusion criterion for study design or specific methodology was used so as to increase the search sensitivity. Studies containing the following characteristics were included (PICO framework):

- Individuals providing unpaid care for family members living with dementia (population).

- Interventions including health-promoting self-care strategies/models (intervention/experience).

- General population, carers receiving treatment as usual or placebo, other disease groups, or no control (control).

- Health-promoting self-care (either as an outcome measure or mediating variable), health behavior, physical and mental health-related outcomes (outcomes/variables).

\section{Exclusion criteria}

Editorials, opinion papers, dissertations, and conference abstracts were not included. Publications which focused 
on carer-management of the dementia symptoms, methodological papers on adherence to interventions, service use or help-seeking behavior were excluded. Articles that did not report any intervention were excluded.

\section{Search outcome}

First, titles and abstracts were reviewed (Figure 1). Relevant articles were read in full and selected by two reviewers independently (DO/LS). A third reviewer (MO) was consulted in cases of disagreement between the two reviewers regarding study inclusion. Quality appraisal is not usually carried out in scoping reviews as the amount of data included is normally large and data synthesis is minimal. ${ }^{21}$ Therefore, all the eligible papers were submitted to data extraction $(n=7)$ according to the guiding review question.

\section{Expert consultation}

As required by the scoping review framework adopted, ${ }^{21}$ an expert consultation was also undertaken. Fifteen research experts in the fields of family carers' health and selfcare were identified via the papers found in the literature search. These experts were invited to complete an online questionnaire containing eleven open questions regarding the following topics: relevance of this field of research; current approaches to health-promoting self-care and self-management in carers; gaps, limitations, strengths and future directions in the field. A total of eight clinical and academic experts in dementia caregiving returned completed questionnaires, including seven professors. These included research psychologists $(n=5)$ and nurses $(n=3)$ by background, from the UK, the Netherlands, USA, Finland, and Sweden. One was from the World Health Organization and another from the Eurocarers organization.

\section{Data extraction and synthesis}

After being read several times, the included papers $(n=7)$ had their aims, sample characteristics, study design, intervention characteristics, outcome measures, and key results extracted. The information collected via the questionnaires sent to the experts was collated and discussed between the research team. The findings were compared with the articles identified in the literature search. A narrative approach was used to discuss the scoping review results and the expert comments aiming to situate the review findings within the broader research and practice contexts. ${ }^{23}$

\section{Results}

This scoping review included seven interventions aimed at improving health-promoting self-care in family carers of people with dementia (Table 1). Six of them were

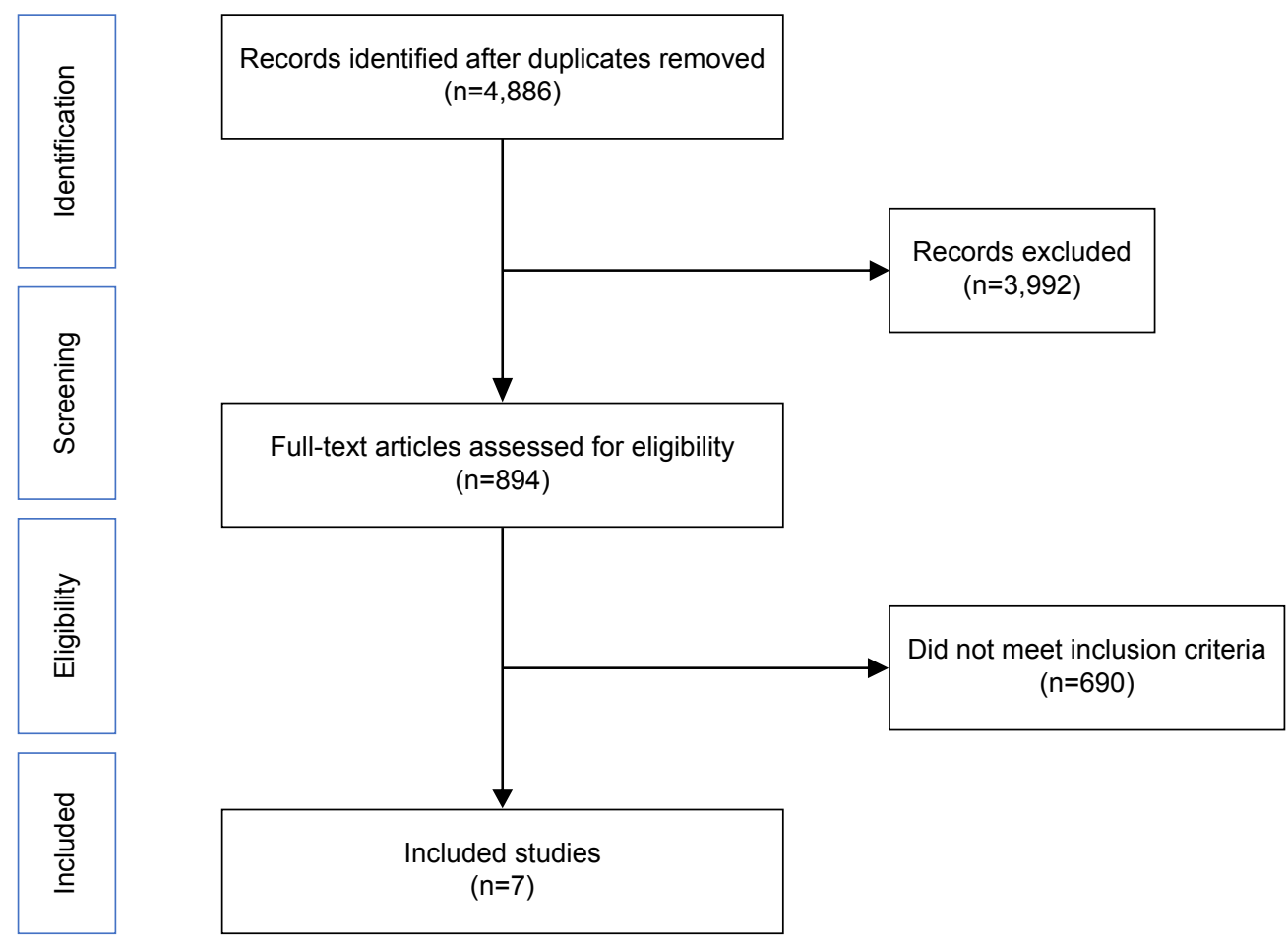

Figure I Flowchart showing the number of studies identified and selected for inclusion. 
Table I Summary of interventions to increase health-promoting self-care behavior and physical exercise in carers of people with dementia $(n=7)$

\begin{tabular}{|c|c|c|c|c|c|}
\hline $\begin{array}{l}\text { Reference, } \\
\text { location }\end{array}$ & Aim & Sample & Design & Intervention & $\begin{array}{l}\text { Outcome measures and } \\
\text { results }\end{array}$ \\
\hline $\begin{array}{l}\text { Farran et al, } \\
\text { United States }{ }^{24}\end{array}$ & $\begin{array}{l}\text { To test a carer skill building } \\
\text { program for managing } \\
\text { dementia behavior }\end{array}$ & $\mathrm{n}=295$ & $\begin{array}{l}\text { Randomized } \\
\text { controlled trial }\end{array}$ & $\begin{array}{l}\text { I2-week session, } 5 \text { group } \\
\text { sessions and } 7 \text { individualized } \\
\text { telephone-based sessions about } \\
\text { managing dementia behavior }\end{array}$ & $\begin{array}{l}\text { Reduced depression in both } \\
\text { groups }(P<0.05) \text {, but no } \\
\text { difference in efficacy }\end{array}$ \\
\hline $\begin{array}{l}\text { Belle et al, } \\
\text { United States }{ }^{30}\end{array}$ & $\begin{array}{l}\text { To test a structured multi- } \\
\text { component intervention in } \\
\text { a diverse ethnic group of } \\
\text { carers }\end{array}$ & $n=642$ & $\begin{array}{l}\text { Randomized } \\
\text { controlled trial }\end{array}$ & $\begin{array}{l}\text { I2-month in-home and } \\
6 \text { telephone-based sessions of a } \\
\text { carer skill building program }\end{array}$ & $\begin{array}{l}\text { Increased quality of life } \\
(P<0.00 \mathrm{I}) \text {; reduced } \\
\text { depression and problem } \\
\text { behaviors in Latinos } \\
(P<0.00 \mathrm{I}) \text {; no difference in } \\
\text { care-home placement rates }\end{array}$ \\
\hline $\begin{array}{l}\text { Farran et al, } \\
\text { United States }{ }^{26}\end{array}$ & $\begin{array}{l}\text { To evaluate a health- } \\
\text { promoting intervention } \\
\text { designed to improve } \\
\text { physical activity }\end{array}$ & $n=21 I$ & $\begin{array}{l}\text { Randomized } \\
\text { controlled trial }\end{array}$ & $\begin{array}{l}\text { Participation in physical } \\
\text { activities for } 12 \text { months based } \\
\text { on individual goals (telephone/ } \\
\text { face-to-face) }\end{array}$ & $\begin{array}{l}\text { Increased total physical } \\
\text { activity at } 6(P=0.01) \text { and } \\
\text { I } 2 \text { months }(P=0.03) \text {; reduced } \\
\text { burden }(P=0.03) \text { at } 3 \text { months }\end{array}$ \\
\hline $\begin{array}{l}\text { Connell and } \\
\text { Janevic, } \\
\text { United States }{ }^{25}\end{array}$ & $\begin{array}{l}\text { To evaluate a telephone- } \\
\text { based exercise intervention }\end{array}$ & $n=137$ & $\begin{array}{l}\text { Randomized } \\
\text { controlled trial }\end{array}$ & $\begin{array}{l}\text { 6-months telephone-based, } \\
\text { physical exercise-focused, } \\
\text { intervention }\end{array}$ & $\begin{array}{l}\text { Increased exercise levels } \\
(P<0.0 \mathrm{I}) \text { and exercise } \\
\text { self-efficacy }(P<0.0 \mathrm{I})\end{array}$ \\
\hline $\begin{array}{l}\text { Farran et al, } \\
\text { United States }{ }^{27}\end{array}$ & $\begin{array}{l}\text { To develop and test a } \\
\text { multi-component caregiver } \\
\text { skill building web-based } \\
\text { program }\end{array}$ & $\mathrm{n}=100$ & Pilot study & $\begin{array}{l}\text { Online-based modules: } \\
\text { decreasing depressive symptoms } \\
\text { and burden, improving self-care } \\
\text { and social support, and managing } \\
\text { behavioral symptoms }\end{array}$ & $\begin{array}{l}\text { Positive evaluation of the } \\
\text { program; increased caregiving } \\
\text { skill at } 6 / 12 \text { weeks }(P=0.0 \text { I } \\
\text { and } P=0.05 \text {, respectively); } \\
\text { reduced depression }(P=0.01) \text {; } \\
\text { increased positive affect } \\
\text { at } 6 \text { weeks }(P=0.05)\end{array}$ \\
\hline $\begin{array}{l}\text { Teel and } \\
\text { Leenerts, } \\
\text { United States }{ }^{28}\end{array}$ & $\begin{array}{l}\text { To develop a theory- } \\
\text { based intervention } \\
\text { and to describe the } \\
\text { process of evaluating the } \\
\text { implementation }\end{array}$ & $n=6$ & Pilot study & $\begin{array}{l}\text { Telephone-based sessions } \\
\text { by nurses: healthy habits, } \\
\text { self-esteem, positive } \\
\text { thoughts, avoiding overload, } \\
\text { communication, building meaning } \\
\text { and person-centered self-care } \\
\text { strategies }\end{array}$ & $\begin{array}{l}\text { Participants understood the } \\
\text { content and planned to use } \\
\text { the information } \\
\text { Increased awareness about } \\
\text { self-care }\end{array}$ \\
\hline $\begin{array}{l}\text { Lok and } \\
\text { Bademli, } \\
\text { Turkey }^{29}\end{array}$ & $\begin{array}{l}\text { To test a self-care program } \\
\text { on burden and healthy } \\
\text { lifestyle }\end{array}$ & $n=40$ & Pilot study & $\begin{array}{l}\text { Seven sessions: strengthening the } \\
\text { carer, decreasing burden, and } \\
\text { promoting healthy lifestyle }\end{array}$ & $\begin{array}{l}\text { Reduced burden and } \\
\text { increased healthy lifestyle } \\
\text { behaviors }\end{array}$ \\
\hline
\end{tabular}

delivered via telephone or combined face-to-face with telephone-based activities, and one was online. Interventions were focused on managing dementia behavior, ${ }^{24}$ promoting physical activity, ${ }^{25,26}$ or combined several activities to improve various outcomes, such as social support, psychological skills, and lifestyle. ${ }^{27-29}$ Six interventions were undertaken in the United States and one in Turkey. Four were randomized controlled trials (RCTs) and three were pilot or feasibility studies. Sample sizes varied from $n=137$ to $n=632$ individuals in the RCTs and from $n=6$ to $n=100$ individuals in the feasibility/pilot studies.

None of the studies was specifically focused on improving and measuring health-promoting self-care. They were rather focused on areas that might be associated with health promotion and healthy behavior, such as physical exercise and psychological well-being. Some of the multi-component interventions used "awareness of self-care practices" or "personcentered self-care strategies", ${ }^{28}$ or simply "self-care", ${ }^{26,29,30}$ to refer to health-promoting self-care practices.

In addition, none of the studies used a specific measure of health-promoting self-care to identify improvements in this area. Rather, they used more generic outcome measures, such as depression, burden, and quality of life.

\section{RCTs}

A telephone-based intervention to increase physical activity in women caring for their spouses with dementia $(n=137)$ showed greater improvement in total exercise in the intervention group 
$(P<0.01)$ when compared with the control group..$^{25}$ Although exercise self-efficacy improved in the post-intervention assessment when compared to baseline $(P<0.01)$, there were no differences in exercise self-efficacy between control and intervention groups. At 6 months, the effect sizes were 0.15 and 0.04 for total exercise and exercise self-efficacy, respectively. Only exercise self-efficacy was significant at 12 months $(P<0.05)$. This intervention used a flexible approach with individualized goals that were set by the participants in conjunction with a counselor.

Belle et a ${ }^{30}$ tested the effects of a structured multicomponent intervention in a diverse ethnic group of carers $(\mathrm{n}=211)$. This intervention was delivered through 12-month in-home and six telephone-based sessions focused on a "carer skill building program" involving managing depression, burden, self-care, healthy behaviors, social support, and dementia behaviors. The intervention increased quality of life $(P<0.001)$, helped reduce depression and problem behaviors in Latinos $(P<0.001)$, but no difference was found in care-home placement rates of their relatives with dementia.

Three studies (two RCTs and one pilot study) involved the same structured multi-component intervention called "carer skill building", ${ }^{31}$ which includes activities for promotion of self-care and healthy behavior (eg, a health booklet provided reminders about health maintenance activities and a tool to record health information and health appointments for both themselves and the care recipients). One RCT $(n=211)$ tested the effects of an individualized, physical activity intervention in comparison to the "carer skill building" control group (only the module focused on managing dementia behaviors was applied). ${ }^{26}$ The intervention showed a significant improvement in total physical activity $(P=0.01)$ and decreased burden $(P=0.03)$. A second study $(\mathrm{n}=295)$ compared the effects of the "carer skill building" program in relation to an information- and support-oriented control group ${ }^{24}$ and showed that "carer skill building" significantly improved depression levels $(P<0.05)$, but no difference in efficacy was found between the two groups. These three RCTs suggested that the "carer skill building" program might be effective to improve carers' mental health.

\section{Pilot and feasibility studies}

Farran et a ${ }^{27}$ developed an online version of the "carer skill building" program and tested its benefits with 100 carers. Results showed a significant increase in caring skill at 6 and 12 weeks and improvements in carer depressive symptoms $(P=0.01)$ and positive affect at 6 weeks $(P=0.05)$. A feasibility study of another theory-based intervention delivered via telephone by nurses $(n=6)$ showed preliminary evidence of enhanced awareness of self-care practices in carers. ${ }^{28}$ The training was focused on healthy habits, self-esteem, positive thoughts, avoiding role overload, communicating, building meaningful and person-centered self-care strategies. Lok and Bademli ${ }^{29}$ examined the effects of a self-care program on burden and healthy lifestyle behavior in a pilot study $(n=40)$ and found a reduction in the perceived burden and enhanced lifestyle behaviors. The program was based on seven sessions for "strengthening" the carer and suggested decreased burden and promotion of healthy behaviors.

\section{Expert consultation}

Overall, experts suggested that research on family carers' health and health-promoting self-care is limited and further investigations using a broader approach to health and selfcare are needed (Figure 2). Experts said that carers have more health problems than the general population because of the high caregiving demands, limited time for themselves, sleep deprivation, social isolation, poor diet, lack of ability to exercise, lack of social and emotional support, poor coping strategies, substance misuse, and untreated mental and physical health problems. Service providers often do not consider carers' advanced age, preparedness to provide care, physical health, mental health, and reluctance to accept support before carers reach a crisis point. There is a lack of regular respite breaks, poor knowledge about the available support services in place, and a lack of national protocols in place to protect carers' health. Services should provide more information, training, support, and advice. These should be more familycentered, more empathetic, and sensitive to carers' needs, there should be earlier identification and exposure to respite care, and there should be annual health checks and "case managers" for every carer.

Experts recommended that research in this area should be flexible, focused on psychosocial interventions considering carers' expectations, goals, acceptance, their own needs, and importance of self-care. These should be person-centered and context specific. Outcome measures to be considered are selfcare, functional decline, health care utilization, self-efficacy, well-being, depression, anxiety, burden, stress, carer experience, quality of life, coping strategies, preparedness to care, satisfaction, resilience, and delay in care-home placement. "Maintenance of health" should be avoided as a parameter due to initial differences in health and the likelihood that impact on health is longer-term, rather than short-term. Researchers should 1) think carefully about the intervention dosage; 2) consider the carers' capacity to participate in 


\section{Causes of poor health in carers of people with dementia}

1. Health promoting self-care interventions are scarce and are not person-centered

2. High demands; limited time; long-term/burdensome care; social isolation; untreated mental and physical problems/symptoms

3. Carer old age

4. Problems with caregiving relationships, sense of obligation, guilt, lack of trust in services

5. Waiting until crisis point

6. The capacity to provide care and the carer health status are often not considered

7. Lack of regular breaks and knowledge about sources of support

8. Lack of national protocols for assessment and monitoring of carers' health needs

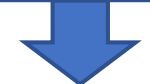

Health-promoting self-care interventions

1. Psychosocial interventions should focus on carers' expectations, goals, acceptance, their own needs and importance of self-care

2. Interventions should be person-centered and context specific to suit carers' preferences and needs, according to carers' age, access to support, length of time as carer, dementia stage, personality and coping resources and strategies

3. Blended approach interventions are useful (eg, face-to-face and online, one-to-one and in groups)

4. Co-designed

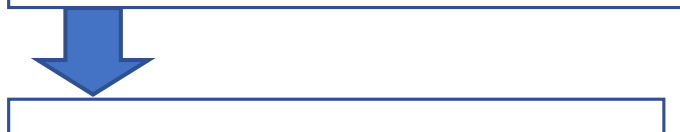

\section{To measure effectiveness}

1. Consider type of intervention and method of delivery

2. Outcome measures: self-care, functional decline, health care utilization, self-efficacy, well-being, depression, anxiety, burden, experience, quality of life, coping, preparedness to care, resilience and delay in institutional care (planned entry to long-term care, as opposed to entry because of a crisis)

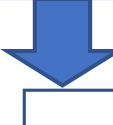

Services should provide
1. Family-centered support
2. Assessment of capacity to provide care and to monitor
status/needs
3. More clinical specialists
4. Earlier identification and exposure to regular respite
5. Education/strategies to monitor own well-being
6. Annual physical and mental health assessments
('health passport')
7. Welcoming and easy to use services
8. An understanding, empathic and knowledgeable individual
mentor
To optimize intervention success
it flexible - day and time that is suitable for carers
ince power relationships
vide a precise intervention dosage
sider carer capacity and readiness to participate
sider different dementia stages
k carefully about how to frame the intervention

Figure 2 Expert suggestions.

specific self-care approaches and their readiness to change lifestyle; 3) avoid "one size fits all" approaches; 4) consider different dementia caregiving stages; 5) be mindful to power relationships and levels of engagement and acceptance; 6) use a co-design or structured peer to peer support; 7) implement interventions with fidelity; and 8) involve multiple health and social sectors.

\section{Discussion}

This is the first scoping review to explore the potential benefits of health-promoting self-care interventions in family carers of people with dementia. Seven relevant studies were highly heterogeneous in content, method of delivery, and outcome measures, and the vast majority was conducted in the United States. None of the studies specifically focused on improving and measuring health-promoting self-care, but on areas that might be more broadly associated with health promotion and healthy lifestyle activities, such as physical exercise. Overall, interventions helped reduce carer depression and burden and increased quality of life, positive affect, physical activity, and exercise self-efficacy. The expert panel considered this area of research important and recommend that future interventions should involve carers' preparedness and capacity to adhere to self-care practices. Carers' age and culture should be considered and a person-centered approach should be used. Important consideration also needs to be given to the fidelity of the intervention and to delivering the right dosage, so that not too much (causing a burden on carers) or not too little (low impact) of the intervention is offered.

Although the quality of the studies was not assessed as part of this scoping review, some methodological considerations can be made based on current minimum standards 
for psychosocial interventions. ${ }^{32}$ For example, the high heterogeneity of the studies in terms of scope, content, and outcome measures limited comparisons and would not allow for a meta-analysis to be undertaken to establish efficacy. Even though some of the multi-component interventions included "self-care" as a domain, none of the interventions used a specific measure of health-promoting self-care to evaluate improvement in self-care behavior and its impact on carer outcomes. This might be because the first theorybased measure to assess health-promoting self-care behavior appears to have been developed only in $2018,{ }^{33}$ by which time only instruments to address barriers and facilitators to self-care had been developed and the studies had already been carried out. We are therefore unable to affirm whether the benefits from the interventions were due to a direct effect of an increase in carers' health-related self-care behavior or due to an improvement in other outcomes (eg, increase in knowledge, reduction in burden). Comments from the expert panel indeed confirmed that research in this area needs to be more robust and that the outcome measures used need to be chosen with caution so that the importance of such health behavior for carers can be established. Although heterogeneous, the interventions showed some benefits to carer outcomes, thus future research could further explore the concept of health-promoting self-care and its use with family carers considering such findings.

Greaves and Campbel1 ${ }^{11}$ noted most of the self-care research has a "self-management approach" to specific illnesses, such as the individual's capacity to manage his/her diabetes or asthma, rather than to the individual's capacity to manage and maintain health and well-being more broadly. However, health-promoting self-care behavior goes beyond managing specific diseases or adhering to specific lifestyle behaviors, such as physical exercise. It involves helping individuals make better health choices and to have selfresponsibility, or accountability for actions, regarding their health. ${ }^{9,34}$ We therefore argue that, for carers to engage in health-promoting behavior, they must be motivated to take personal responsibility for their health by promoting self-care agency. Interventions need to ensure that such a key aspect is included as part of the program.

This is important as several studies have shown that family carers of people with dementia often experience "symptoms" of burnout and stress (feeling ill), ${ }^{19}$ but do not necessarily have an identified disease. If such symptoms however are not controlled, these are likely to lead to the onset of diseases (eg, psychiatric morbidity, stress-related high blood pressure) and early mortality in the long run. ${ }^{35}$ Based on this review's results, we recommend that future interventions in this area should be focused on promoting carers' ability to manage their own health and symptoms and "self-care agency" to take action. Such skill is likely to translate into carers feeling prepared to manage several health behaviors, and not only physical exercise or specific diseases, eg, and therefore will have a higher impact.

Multi-component interventions using individualized or person-centered approaches had an overall positive effect on carer outcomes. ${ }^{36}$ The combination of telephone and one-to-one/group interventions also seemed to be beneficial. As most were from the United States, future interventions need to involve carers from a wider variety of cultural and ethnic backgrounds to establish the relevance and effectiveness of such programs in different carer groups. Self-care practices are likely to vary according to the public resources available, family dynamics, social capital, and health literacy. Promotion of health-related self-care thus requires an understanding of the individual's own self-care practices and needs to be understood in the context of health care pluralism. ${ }^{19}$ We thus argue that self-care behavior is a life-long issue which might be affected not only by providing care, but also by previous experiences with health as well as socioeconomic circumstances. Longitudinal, multi-level and multi-component interventions measuring the effects of several variables on health-promoting self-care and health outcomes are needed to better understand how these various factors inter-relate across time.

One of the largest RCTs included in this scoping review found no significant effects regarding care-home placement, though it did improve carer quality of life, depression, and problem behaviors in their relatives with dementia. ${ }^{30}$ Even though this was a multi-component intervention covering management of depressive symptoms, burden, self-care, healthy behaviors, social support, and dementia behaviors, it may have failed to tackle carer's ability to continue to provide care for the person with dementia at home. It might also be the case that people being cared for had dementia too advanced at the time of the study, which meant that more carers in this study felt the need for residential care. This could also mean that the intervention may have helped carers prioritize their own needs, which may have led to easier acceptance of formal care and positive impact on carers' health and well-being. Nonetheless, the lack of impact on care-home placement has social and economic implications and the reasons for that should be further explored in future research.

\section{Conclusion}

This scoping review explored the potential benefits of health-promoting self-care interventions in family carers 
of people with dementia. High heterogeneity was identified in the interventions in terms of methodology and the vast majority was conducted in the United States. None of the interventions had a particular focus on improving and measuring health-promoting self-care, but were rather related to areas that might be more broadly associated with health promotion and healthy lifestyle activities, such as physical exercise. Overall, interventions helped to reduce carer depression and burden, and increased quality of life, positive affect, physical activity, and exercise self-efficacy. The expert panel considered this area of research important and recommend that future interventions should involve carers' preparedness and capacity to adhere to self-care practices. Future studies should use more specific, validated tools to evaluate this construct so that a meta-analysis could be carried out to establish evidence of efficacy in relation to this. These should also be implemented with fidelity and should use a person-centered approach. A life-span and personcentered approach to health-promoting activities might be more likely to be successful with family carers.

\section{Acknowledgments}

This review was funded by the Nottinghamshire Clinical Commissioning Group (Research Capability Funding 2016/2017).

This review was presented at the Alzheimer's Association International Conference in July 2018 as part of a poster presentation and the poster's abstract has been published. ${ }^{37}$

\section{Author contributions}

All authors contributed toward data analysis, drafting and critically revising the paper, gave final approval of the version to be published, and agree to be accountable for all aspects of the work.

\section{Disclosure}

The authors report no conflicts of interest in this work.

\section{References}

1. Moon H, Dilworth-Anderson P. Baby Boomer caregiver and dementia caregiving: findings from the national study of caregiving. Age Ageing. 2015;44(2):300-306.

2. Luchesi BM, Degani GC, Brígola AG, Pavarini SCI, Marques S. Evaluation of depressive symptoms in older caregivers. Arch Clin Psychiatry. 2015;42(2):45-51.

3. Sörensen S, Conwell Y. Issues in dementia caregiving: effects on mental and physical health, intervention strategies, and research needs. Am J Geriatr Psychiatry. 2011;19(6):491-496.

4. Schulz R, Sherwood PR. Physical and mental health effects of family caregiving. Am J Nurs. 2008;108(9 Suppl):23-27.

5. Fredman L, Cauley JA, Hochberg M, Ensrud KE, Doros G, Study of Osteoporotic Fractures. Mortality associated with caregiving, general stress, and caregiving-related stress in elderly women: results of caregiver-study of osteoporotic fractures. J Am Geriatr Soc. 2010;58(5):937-943.
6. Parker G, Arksey H, Harden M. Meta-review of international evidence on interventions to support carers. Social Policy Research Unit, University of York; 2010. Available from: https://www.york.ac.uk/ inst/spru/research/pdf/CarersLit.pdf. Accessed February 21, 2019.

7. Hoff A. Current and future challenges of family care in the UK. Future of an ageing population: evidence review. Government office for science. London, UK: Crown; 2015:1-35.

8. Mark RE. Promote the health of dementia caregivers. Am J Alzheimers Dis Other Demen. 2016;31(2):181-183.

9. Acton GJ. Health-promoting self-care in family caregivers. Western $J$ Nurs Res. 2002;24(1):73-86.

10. UK National Health System (NHS). Patient activation: People's ability to manage their own health and wellbeing. Available from: https:// www.england.nhs.uk/ourwork/patient-participation/self-care/patientactivation/. Accessed February 21, 2019.

11. Greaves CJ, Campbell JL. Supporting self-care in general practice. Br J Gen Pract. 2007;57(543):814-821.

12. WHO. Self-Care In The Context of Primary Health Care. Geneva: World Health Organization; 2009.

13. Matarese M, Lommi M, de Marinis MG. Systematic review of measurement properties of self-reported instruments for evaluating self-care in adults. J Adv Nurs. 2017;73(6):1272-1287.

14. de Silva D. Helping people help themselves: a review of the evidence considering whether it is worthwhile to support self-management. The Evidence Centre. London: Health Foundation; 2011.

15. Wilkinson A, Whitehead L. Evolution of the concept of self-care and implications for nurses: a literature review. Int J Nurs Stud. 2009;46(8): 1143-1147.

16. Godfrey C, Harrison MB, Lysaght R, Lamb M, Graham ID, Oakley P. Care of self - care by other - care of other: the meaning of self-care from research, practice, policy and industry perspectives. Int $J$ Evid Based Healthc. 2011;9(1):3-24.

17. Kemppainen V, Tossavainen $K$, Turunen H. Nurses' roles in health promotion practice: an integrative review. Health Promotion International. 2013;28(4):490-501.

18. van Hooft SM, Been-Dahmen JMJ, Ista E, van Staa A, Boeije HR. A realist review: what do nurse-led self-management interventions achieve for outpatients with a chronic condition? J Adv Nurs. 2017;73(6): $1255-1271$.

19. Mackichan F, Paterson C, Henley WE, Britten N. Self-care in people with long term health problems: a community based survey. BMC Fam Pract. 2011;12(1):53-53.

20. Tricco AC, Lillie E, Zarin W, et al. A scoping review on the conduct and reporting of scoping reviews. BMC Med Res Methodol. 2016; 16(1):15.

21. Armstrong R, Hall BJ, Doyle J, Waters E. Cochrane Update. "Scoping the scope" of a cochrane review. J Public Health. 2011;33(1):147-150.

22. Arksey H, O'Malley L. Scoping studies: towards a methodological framework. Int J Soc Res Methodol. 2005;8(1):19-32.

23. Levac D, Colquhoun H, O'Brien KK. Scoping studies: advancing the methodology. Implement Sci. 2010;5(1):69.

24. Farran C, Gilley D, Mccann J, Bienias J, Lindeman D, Evans D. Psychosocial interventions to reduce depressive symptoms of dementia caregivers: a randomized clinical trial comparing two approaches. J Ment Health Aging. 2004;10(4):337-350.

25. Connell CM, Janevic MR. Effects of a telephone-based exercise intervention for dementia caregiving wives: a randomized controlled trial. J Appl Gerontol. 2009;28(2):171-194.

26. Farran CJ, Paun O, Cothran F, et al. Impact of an individualized physical activity intervention on improving mental health outcomes in family caregivers of persons with dementia: a randomized controlled trial. AIMS Med Sci. 2016;3(1):15-31.

27. J Farran C, Zurawski P, R Inventor B, Urbanic J, Paun O. An evidencebased technological caregiver skill building intervention for dementia family caregivers: pilot study. Alzheimers Dement Cogn Neurol. 2017; 1(1):1-7.

28. Teel CS, Leenerts MH. Developing and testing a self-care intervention for older adults in caregiving roles. Nurs Res. 2005;54(3):193-201. 
29. Lök N, Bademli K. Pilot testing of the "First You Should Get Stronger" program among caregivers of older adults with dementia. Arch Gerontol Geriatr. 2017;68:84-89.

30. Belle SH, Burgio L, Burns R, et al. Enhancing the quality of life of dementia caregivers from different ethnic or racial groups: a randomized, controlled trial. Ann Intern Med. 2006;145(10):727-738.

31. Gitlin LN, Winter L, Corcoran M, Dennis MP, Schinfeld S, Hauck WW. Effects of the home environmental skill-building program on the caregiver-care recipient dyad: 6-month outcomes from the Philadelphia reach initiative. Gerontologist. 2003;43(4):532-546.

32. Montgomery P, Grant S, Mayo-Wilson E, et al. Reporting randomised trials of social and psychological interventions: the CONSORT-SPI 2018 extension. Trials. 2018;19(1):407.

33. Riegel B, Barbaranelli C, Sethares KA, et al. Development and initial testing of the self-care of chronic illness inventory. Journal of Advanced Nursing. 2018;74(10):2465-2476.
34. Callaghan DM. Health-Promoting Self-Care Behaviors, Self-Care Self-Efficacy, and Self-Care Agency. Nursing Science Quarterly. 2003; 16(3):247-254.

35. Caputo J, Pavalko EK, Hardy MA. The long-term effects of caregiving on women's health and mortality. J Marriage Fam. 2016;78(5):1382-1398.

36. Elvish R, Lever S-J, Johnstone J, Cawley R, Keady J. Psychological Interventions for Carers of People With Dementia: A Systematic Review of Quantitative and Qualitative Evidence. Lutterworth, Leicestershire: British Association for Counselling \& Psychotherapy; 2012.

37. Oliveira D, Orrell M, Radburn J. Health-promoting self-care in family carers of people with dementia [abstract]. Alzheimers Dement 2018;14(7;Suppl):1320. Available from: https://www.alzheimersanddementia.com/article/S1552-5260(18)32053-3/fulltext.
Clinical Interventions in Aging

\section{Publish your work in this journal}

Clinical Interventions in Aging is an international, peer-reviewed journal focusing on evidence-based reports on the value or lack thereof of treatments intended to prevent or delay the onset of maladaptive correlates of aging in human beings. This journal is indexed on PubMed Central, MedLine,

\section{Dovepress}

CAS, Scopus and the Elsevier Bibliographic databases. The manuscript management system is completely online and includes a very quick and fair peer-review system, which is all easy to use. Visit http://www.dovepress. $\mathrm{com} /$ testimonials.php to read real quotes from published authors. 